\title{
PERANAN FITOREMEDIASI PADA LAHAN BEKAS TAMBANG EMAS DI KECAMATAN JONGGAT KABUPATEN LOMBOK TENGAH
}

\author{
Fitriatul Munawarah ${ }^{1}$, Budy Wiryono ${ }^{2}$, Muliatiningsih ${ }^{3 *}$ \\ ${ }^{1,2}$ Teknik Pertanian, Universitas Muhammadiyah Mataram \\ ${ }^{3^{*}}$ Teknik Pertanian, Universitas Muhammadiyah Mataram, muliatiningsih@gmail.com
}

\section{INFO ARTIKEL}

RiwayatArtikel:

Diterima: 17 -07-2017

Disetujui: $20-08-2017$

\section{Kata Kunci:}

Fitoremediasi

Paspalum conjugatum

Lahan bekas tambang

Amonium thiosulfat

Sodium thiosulfat

\begin{abstract}
ABSTRAK
Abstrak: Penelitian ini bertujuan untuk mengetahui peranan Amonium thiosulfat dan Sodium thiosulfat sebagai bahan pengkhelat pada proses Fitoremediasi dengan menggunakan tanaman Paspalum conjugatum (Rumput Paitan). Metode yang digunakan dalam penelitian ini adalah metode eksperimental yang dilakukan di lapangan pada bulan Mei sampai Juli 2017. Penelitian dirancang menggunakan Rancangan Acak Kelompok (RAK) dengan variasi perlakuan: PAT1 = pemberian Amonium thiosulfat sebanyak $1 \mathrm{gr}$, PAT2 = pemberian Amonium thiosulfat sebanyak $2 \mathrm{gr}$, PST1 = pemberian Sodium thiosulfat sebanyak $1 \mathrm{gr}$, PST2 = pemberia Sodium thiosulfat sebanyak $2 \mathrm{gr}$. Setiap perlakuan diulang sebanyak 3 kali sehingga diperoleh 12 unit percobaan. Parameter yang diamati dalam penelitian ini meliputi konsentrasi $\mathrm{Hg}$ pada tanaman, berat berangkasan, dan tinggi tanaman. Data hasil pengamatan dianalisis dengan menggunakan standar deviasi mean. Bahan pengkhelat Amonium thiosulfat lebih tinggi mengikat $\mathrm{Hg}$ di bandingkan dengan Sodium thiosulfat. Konsentrasi kadar total $\mathrm{Hg}$ tertinggi terdapat pada perlakuan Amonium thiosulfat dosis $2 \mathrm{gr} / 15$ liter sebesar 1137,87 ppm. Semakin tinggi konsentrasi $\mathrm{Hg}$ pada tanah mengakibatkan pertumbuhan tanaman terhambat.

Abstract: Ammonium thiosulfate and Sodium thiosulfate as chelating material in the Phytoremediation process using Paspalum conjugatum (Paitan Grass). The method used in this study is an experimental method conducted in the field from May to July 2017. The study was designed using Randomized Block Design (RBD) with a variety of treatments: PAT1 = giving $1 \mathrm{gr}$ Ammonium thiosulfate, PAT2 = giving 2 gr Ammonium thiosulfate giving, PST1 = giving $1 \mathrm{gr}$ Sodium thiosulfate, PST2 = giving 2 grams of Sodium thiosulfate. Each treatment was repeated three times to obtain 12 experimental units. The parameters observed in this study include the concentration of $\mathrm{Hg}$ in plants, the weight of stature, and plant height. Observation data were analyzed using the standard deviation of the mean. The chelating agent Ammonium thiosulfate is higher in binding to $\mathrm{Hg}$ compared to Sodium thiosulfate. The highest concentration of total $\mathrm{Hg}$ was found in Ammonium thiosulfate treatment with a dose of $2 \mathrm{gr} / 15$ liters of $1137.87 \mathrm{ppm}$. The higher the concentration of $\mathrm{Hg}$ on the soil resulted in stunted plant growth.
\end{abstract}

\section{A. LATAR BELAKANG}

Potensi pertambangan emas yang ada di NTB cukup besar, setidaknya ada 16 perusahan yang memiliki izin usaha pertambangan emas dan 67 izin pertambangan rakyat (IPR) yang tersebar diseluruh wilayah NTB. Salah satu dampak negatif yang ditimbulkan akibat penambangan emas oleh rakyat adalah pencemaran merkuri hasil proses pengolahan emas secara amalgamasi. Pada proses amalgamasi emas yang dilakukan oleh rakyat secara tradisional, merkuri dapat terlepas ke lingkungan pada tahap pencucian [1].

Dampak lingkungan akibat penambangan liar atau pertambangan tanpa ijin yaitu tercemarnya lingkungan oleh logam berat $\mathrm{Hg}$ dan logam berat lain seperti As dan Cd. Proses Amalgamasi dengan merkuri ini merupakan proses yang sederhana dan hanya membutuhkan investasi kecil. Namun demikian, pada proses pencucian, limbah yang umumnya masih mengandung merkuri dibuang langsung ke badan air/lahan pertanian [2].

Salah satu metode penanganan lahan bekas tambang yang umum digunakan adalah metode fitoremediasi dengan menggunakan tumbuhan untuk menghilangkan polutan dalam tanah dan air yang terkontaminasi [3]. Keunggulan sistem fitoremediasi adalah ramah lingkungan, murah dan dapat dilakukan secara in situ. Keberhasilan sistem fitoremediasi ditentukan oleh jenis tumbuhan, iklim dan kondisi tailing [4]. Paspalum conjugatum merupakan salah satu tanaman akumulator, dimana Paspalum conjugatum memiliki kemampuan dalam menyerap logam berat dalam tanah dan tingkat adaptasinya tinggi. Penelitian [5] menunjukan hasil serapan tanaman Paspalum conjugatum terhadap merkuri $(\mathrm{Hg})$ lebih tinggi (30,09 ppm) dengan penambahan amonium thiosulfat dibandingkan dengan tanaman lain seperti Cyperus kylingia, dan Lindernia crustacean. 
Penelitian ini bertujuan untuk mengetahui peranan Amoniumthiosulfat dan Sodium thiosulfat sebagai bahan pengkhelat pada proses Fitoremediasi dengan menggunakan tanaman Paspalum conjugatum (Rumput Paitan).

\section{B. METODE PENELITIAN}

Metode yang digunakan dalam penelitian ini adalah metode eksperimental. Penelitian dilakukan di lokasi pembuangan tailing penambang emas skala kecil (PESK) Kecamatan Jonggat, Kabupaten Lombok Tengah pada bulan Mei sampai Juli 2017.

\section{Rancangan Percobaan}

Rancangan yang digunakan adalah Rancangan Acak Kelompok (RAK) dengan 4 perlakuan pemberian bahan pengkhelat yaitu :

PAT1 : Pemberian Amonium thiosulfat 1 g/15 liter/o,001875 ha

PAT2 : Pemberian Amonium thiosulfat 2 g/15 liter/o,001875 ha

PST1 : Pemberian Sodium thiosulfat 1 g/15 liter/o,001875 ha

PST2 : Pemberian Sodium thiosulfat 2 g/15 liter/o,001875 ha

Masing-masing perlakuan diulang 3 kali sehingga diperoleh 12 unit percobaan. Data yang diperoleh di analisis dengan menggunakan Standar Error Mean.

\section{Pelaksanaan Penelitian}

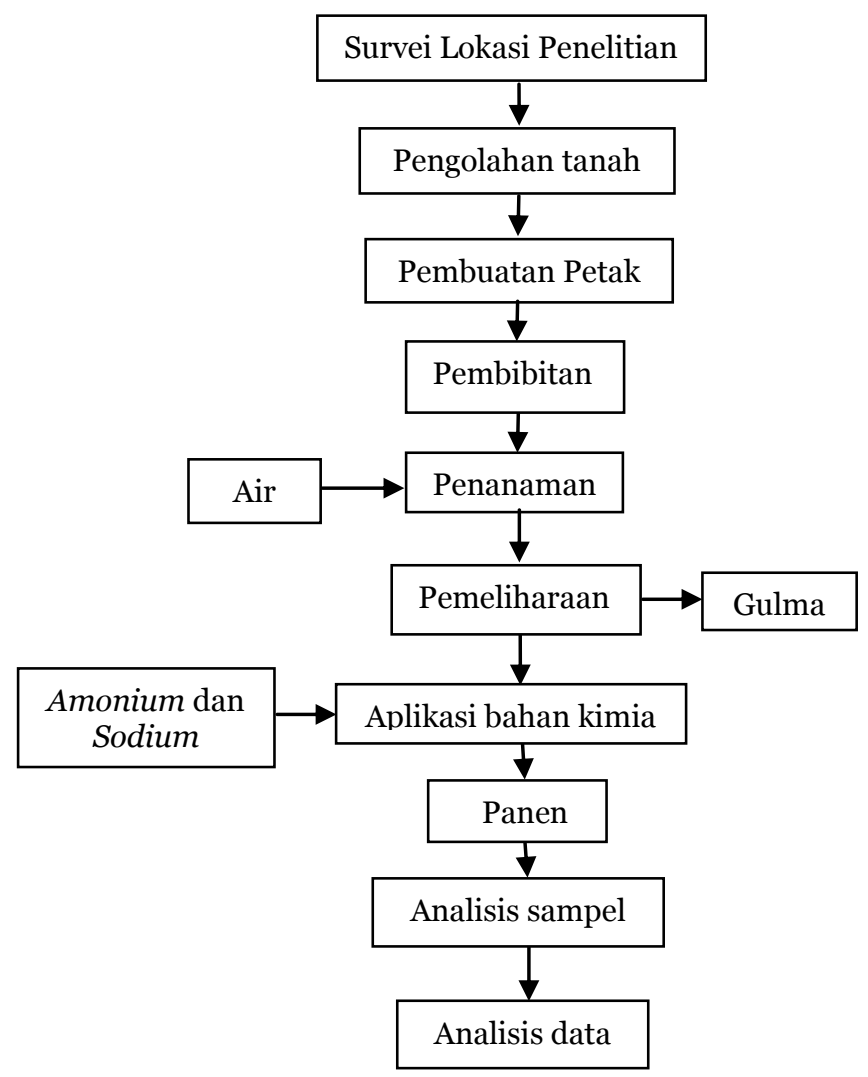

Gambar 1. Diagram alir penelitian

\section{HASIL DAN PEMBAHASAN}

Peranan Amonium thiosulfat dan Sodium tiosulfat terhadap penyerapan $\mathrm{Hg}$ pada Paspalum conjugatum

Amonium thiosulfat dan Sodium thiosulfat mempunyai peranan dalam mengkhelat $\mathrm{Hg}$ sehingga meningkatkan akumulasi $\mathrm{Hg}$ dalam tajuk maupun akar tanaman [6].

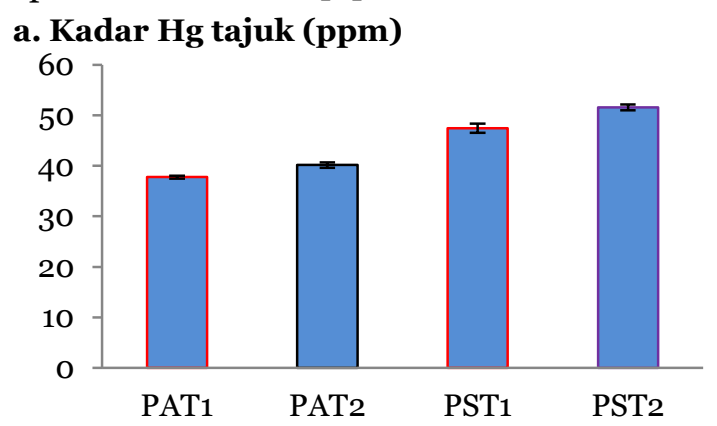

\section{b. Kadar Hg akar (ppm)}

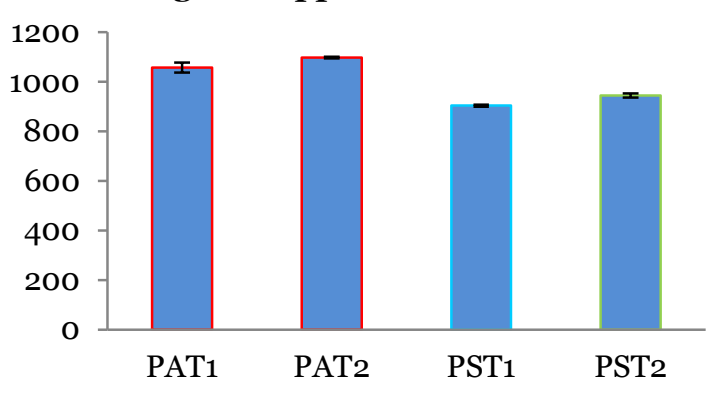

Gambar 2a \& 2b. Data hasil akumulasi Hg pada tajuk dan akar tanaman Paspalum conjugatum

Pada Gambar 2a dan 2b menunjukkan dosis pemberian Amonium thiosulfat maupun Sodium thiosulfat yang meningkat dapat meningkatkan kadar $\mathrm{Hg}$ pada tajuk maupun akar tanaman Paspalum conjugatum.

Pemberian Amonium thiosulfat pada dosis $1 \mathrm{gr}$ maupun dosis $2 \mathrm{gr}$ memberikan hasil yang berbeda nyata dengan pemberian Sodium thiosulfat pada tajuk maupun akar Paspalumconjugatum. Kadar $\mathrm{Hg}$ tertinggi pada tajuk terdapat pada PST2, sedangkan pada akar terdapat pada perlakuan PAT2. Konsentrasi kadar $\mathrm{Hg}$ total tertinggi Paspalum conjugatum terdapat pada perlakuan PAT2 dengan pemberian Amonium thiosulfat2 gr. Hal ini didukung dengan penelitian Handayanto, et al. (2014) yang menunjukan bahwa aplikasi Amonium thiosulfat meningkatkan kadar $\mathrm{Hg}$ dalam tajuk sebesar $76 \%$ dan $45 \%$, serta akar sebesar $39 \%$ dan $26 \%$.

Dalam tanah ion Amonium dilepas dan membentuk sejumlah kecil asam, sambil berkontribusi menyumbang nitrogen esensial untuk pertumbuhan tanaman. Tumbuhan pada saat menyerap logam berat akan membentuk suatu enzim reduktase di membran akarnya. Reduktase berfungsi mereduksi logam dan diangkut melalui mekanisme khusus di dalam membran akar [7]. 


\section{Berat berangkasan kering tajuk dan akar tanaman}

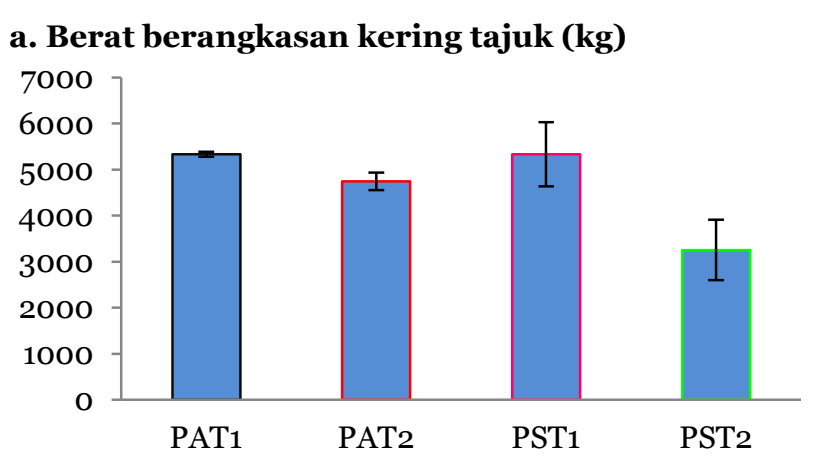

b. Berat berangkasan kering akar (kg)

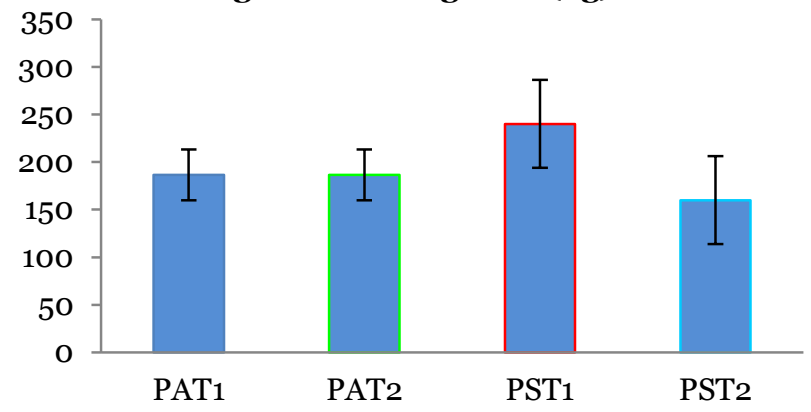

Gambar 3a \& 3b. Berat berangkasan tajuk dan akar tanaman Paspalum conjugatum

Berat berangkasan tajuk tanaman pada perlakuan PAT1 berbeda nyata dengan perlakuan PAT2 dan PST2, tetapi tidak berbeda nyata dengan perlakuan PST1. Hal ini diduga berkaitan dengan tingginya konsentrasi kadar Hg yang ada pada tajuk Paspalum conjugatum dan menjadi racun yang menyebabkan terhambatnya pertumbuhan tanaman. Tingginya nilai berat kering tajuk pada perlakuan PAT1, dikarenakan rendahnya konsentrasi $\mathrm{Hg}$ yang terdapat pada tajuk Pasplum conjugatum. Hal ini juga yang ditunjukkan pada hasil berat berangkasan kering akar Paspalum conjugatum. Semakin tinggi konsentrasi kadar $\mathrm{Hg}$ pada akar, maka berat berangkasan pada akar tersebut semakin menurun.

\section{Tinggi Tanaman}

Tingginya laju pertumbuhan tanaman pada suatu lokasi penelitian tergantung pada kandungan unsur hara pada lahan tersebut. Hal ini dapat dilihat pada gambar 4.

\section{Tinggi tanaman minggu ke-8 (cm)}

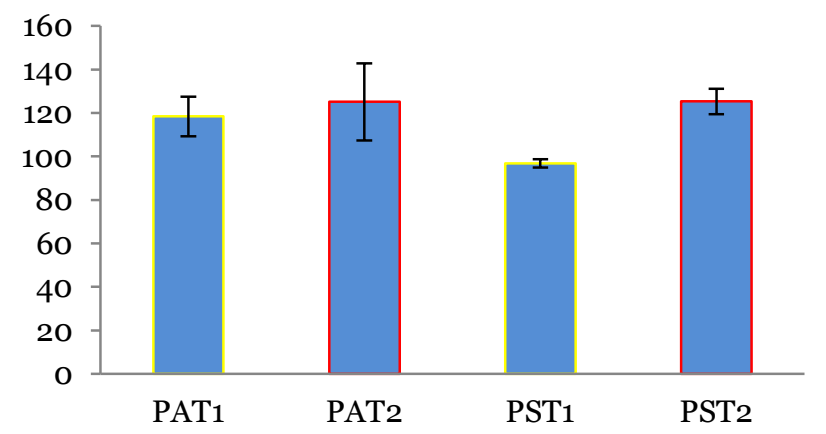

Gambar 4. Tinggi tanaman Paspalum conjugatum umur 8 minggu

Dari Gambar 4. dapat dilihat bahwa tinggi tanaman pada minggu ke 8 menunjukkan hasil pada perlakuan PAT1 tidak berbeda nyata dengan perlakuan PAT2 dan PST2, tetapi berbeda nyata dengan perlakuan PST1. Hal itu disebabkan oleh beberapa faktor yang terjadi pada waktu penelitian diantaranya adalah tingginya kandungan bahan pencemar pada tiap-tiap petak perlakuan sehingga pertumbuhan tanaman terhambat.

Tinggi tanaman sangat dipengaruhi oleh lingkungan sekitar, kondisi medium yang baik menyebabkan pertumbuhan akar tanaman dapat berkembang baik, sehinggga proses penyerapan air dan unsur hara menjadi lancar. Jjika perakaran tanaman berkembang dengan baik maka pertumbuhan bagian tanaman lainnya juga akan baik pula karena akar mampu menyerap air dan unsur hara yang dibutuhkan oleh tanaman.

Masuknya logam berat dalam tanah akan menyebabkan penurunan kualitas sifat kimia tanah, karena menyebabkan unsur hara yang terdapat di dalam tanah menjadi tidak tersedia bagi tanaman dan menghambat penyerapan unsur hara.

\section{SIMPULAN DAN SARAN}

\section{Simpulan}

Berdasarkan hasil penelitian diperoleh beberapa kesimpulan yaitu sebagai berikut:

a. Bahan pengkhelat Amonium thiosulfat lebih tinggi mengikat $\mathrm{Hg}$ di bandingkan dengan Sodium thiosulfat.

b. Konsentrasi kadar total $\mathrm{Hg}$ tertinggi terdapat pada perlakuan Amoniumthiosulfat dosis 2 gr/15 liter sebesar 1137,87 ppm.

c. Semakin tinggi konsentrasi $\mathrm{Hg}$ pada tanah mengakibatkan pertumbuhan tanaman terhambat.

\section{Saran}

Berdasarkan kesimpulan yang terbatas pada hasil penelitian ini, maka dapat diajukan beberapa saran sebagai berikut:

a. Untuk mendapatkan hasil serapan merkuri (Hg) yang tinggiperlu menambahkandosis bahan pengkhelat .

b. Untuk memaksimalkan penyerapan merkuri (Hg) oleh tanaman perlu menjaga kebersihan tanaman dari tanaman lain atau gulma.

c. Perlu dilakukan penelitian lebih lanjut untuk mengetahui adanya bahan pencemar lain yang terserap oleh Paspalumconjugatum selain $\mathrm{Hg}$.

\section{E. DAFTAR RUJUKAN}

[1] Widhiyatna, D.2005. Pendataan Penyebaran Merkuri Akibat Pertambangan Emas di Daerah Tasikmalaya, 
Jurnal Agrotek Ummat, Vol. 4 No.2. Agustus 2017 / Peranan Fitoremediasi Pada Lahan Bekas Tambang Emas Di Kecamatan Jonggat Kabupaten Lombok Tengah/Fitriatul Munawarah, Budy Wiryono, Muliatiningsih.

Propinsi Jawa Barat. Kolokium Hasil Lapangan-DIM 2005.

[2] Palapa,T.M, 2009. Bioremediasi Merkuri (Hg) dengan Tumbuhan Air Sebagai Salah Satu Alternatif Penanggulangan Limbah Tambang Emas Rakyat. Jurnal : Agritek Vol.17 No.5, September 2009.

[3] Purwantari, N. D. 2007. Reklamasi Area Tailing Di Pertambangan Dengan Tanaman Pakan Ternak; Mungkinkah ? BuletinWartazoa17 (3): 101-108.

[4] Juhaeti, T, Syarif N, Sambas E.N. Hoesen, DSH, 2005. Karakteristik Jenis Tumbuhan pada Vegetasi di Lokasi Tailing Pond Pasir Gombong PT. ANTAM dan Penambangan Emas Tanpa Izin (PETI) Cikotok. Laporan Teknik, 2005.

[5] Handayanto, E., Prasetyo, B., Muddarisna, N. 2012. Fitoremediasi Tanah Tercemar Merkuri Limbah Tambang Emas Rakyat untuk Perbaikan Produksi Jagung. Laporan Penelitian Hibang Bersaing Institusi, Universitas Brawijaya. Dibiayai oleh Direktorat Jenderal Pendidikan Tinggi, Kementerian Pendidikan dan Kebudayaan, Melalui DIPA Universitas Brawijaya nomor : 0636/02304.2.16/15/2012, tanggal 9 Desember 2011, dan berdasarkan SK Rektor Universitas Brawijaya Nomor : 366/SK/2012 tanggal 13 Agustus 2012.

[6] Handayanto, E., Muddarisna, N. and Krisnayanti, B.D. 2014. Induced Phytoextraction Of Mercury And Gold From Cyanidation Tailings Of Small-Scale Gold Mining Area of West Lombok, Indonesia.

[7] Ghosh, M. and Singh, S.P. 2005. A Review On Phytoremediation Of Heavy Metals And Utilization Of Its By Product. 